\title{
多変数系の同定
}

古田勝. 久. 河注 植*

東京工業大学工学部 東京都目黒区大岡山 2-12-1

(昭和 46 年 11 月 29 日 受付)

\section{Identification of Multivariable Systems}

\author{
Katsuhisa Furuta and Joo Shik HA \\ (Tokyo Institute of Technology, Meguro-ku, Tokyo)
}

(Received November 29, 1971)

This paper presents an identification procedure for a multivariable system based on the system theory developed recently. In this procedure, the pulse transfer function is identified from the input and the output data, and the minimum dimensional realization is derived. Even in case that the input-output data are contaminated by noise, a slight modification of the method for noiseless case maked it possible to identify the pulse transfer function, and to realize the system. practically by defining the $\varepsilon$-practical controllability. This paper also clarifies that the minimal realization gives the so-called order of the system.

\section{1. 緒 言}

システム工学に和いて最も重要なことがらは, 対象 とするシステムのモデル作りであり，これまでいろい ろのモデリ゙ングの手法が開発提案されている：されら の方法はいずれも対象とするシステムを機能の最小単 位を表わすと考光られるサブンステムに分解し，・各サ ブシステムの機能を単純化あるいは理想化して数学的 に表現し; 全体のシステムの数式モデルを作る。乙しし て, このように作られた数式モデル中に含まれる未知
パラメータをシステムへの入出力データから固定し, モデル作りが行な和秃ると考光られてきた。すなおち Fig. 1 で与光られるよらな手順でモデルが作られてき た。これまで制御工学の同定理論に永いては主に Fig. 1 の 5., の階段であるパラィータ推定法の開発に重点 が置かれてきた。

しかるに, 最近の Kalman $5^{42,5)}$ とよる線形システ ム理論の発達は, システムの入力-出力関係と, 状態 変数記述の関保を明確にし数式モデルが状態変数記述 のとき状態方程式の係数行列中の, 未知パラメータは

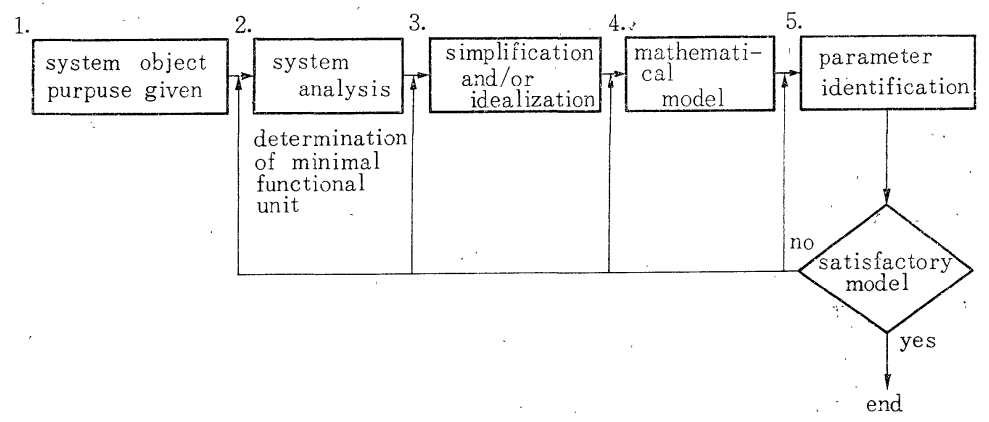

Fig. 1 Modelling process.

\footnotetext{
* 現在, 韓国海洋大学勤務.
} 
一意には決められないことを示した ${ }^{4) ~ 6)}$. そして入出 力関係を満たす最小次元のシステムの状態変数記述を 求める (minimal realization) 問題が，広く研究さ れ始めだ4〜7)。

本研究は，これら最近のシステム理論の成果を用い て, 与えられた入力出力をもつ最小次元の多変数系を 同定するアルゴリズムを求めることを目的としたもの である.2. では，伝達関数と状態変数記述の基本的 関係を述べた。3、では，ノイズに活されない入出力 データが与兄られとさ，これらを入出力とする。仮 定した次数の伝達関数をもつ多变数亲が存在するため の必要十分条件が与えられ，同時に多変数系の未知 ラメータを求めるアルゴリズムも与兄られた。さらに 求められた伝達関数を Mayne ${ }^{6)}$ の方法を改良した方 法で，最小次元状態変数記述できることを示した４. では，ノイズに污されたデータが与兄られる場合も著 者の提案した同定法 ${ }^{8)}$ を多変数系へ応用することによ りノイズのない場合と同様にとり扱えることを示した。 5. では簡単な例題を用いて提案する同定法の有用性 を示した。

\section{2. 多変数系の表現}

本報告で得られた結果を連続なシステムの同定に拡 張することは容易であるが，本報告では定常離散值系 の同定問題だけについて考える. $m$ 個の入力 $u \in R^{m}$ と $p$ 個の出力 $y \in R^{p}$ を字定常線形離散值系 $\sum$ は,

$$
\Sigma: \begin{aligned}
& x(t+1)=F x(t)+G u(t) \\
& y(t)=H x(t)
\end{aligned}
$$

と表わすことができる． $x \in R^{m}$ をシステム $\sum$ の状態 (state), $n$ を の次元といい，このよらなシステム の表現をシステムの状態変数記述，あるいは内部記述 という.ただし， $t$ は整数值をとり，

$F: n \times n, G: n \times m, H: p \times n$ 行列である.

単位時間推移オペレータを $\boldsymbol{z}$ とするとシステム $\boldsymbol{\Sigma}$ のパルス伝達関数 $R(z)$ は $(1)$ ，（2）式から,

$$
R(z)=H(z I-F)^{-1} G
$$

すなわち $\Sigma(F, G, H)$ が与えられるとき $R(z)$ は 1 価に与えられるが， $R(z)$ が与えられても $\{F, G, H\}$ は 1 価に決められない， $R(z)$ が与えられたとき（3） 式を満たす最小次元システム $\Sigma(F, G, H)$ を求める 問題を最小次元実現問題という。このアルゴリズムは いろいろ提案されているが，基本的に Gilbert の方法 に基づいて，特性方程式の根を求めなければならない ものが多かった．本報告では特性方程式の根を求めな いでも良いアルゴリズムを導出し，それを定理 2 で示 +.
最小次元実現問題は，システムの構造，すなわち controllability, observability と深い関連がある。 これらの概念は,

【定義 1】 (controllability) システム $\sum$ の任 意の時刻 $t_{0}$ に和ける状態 $x_{0}$ を時刻 $t\left(>t_{0}\right)$ で零状

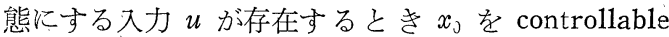
な状態という。状態空間 $R^{n}$ のすべての状態が controllable なとき， $\sum$ が completely controllable と いら.

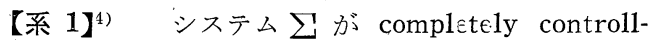
able であるための必要十分条件は,

$$
\operatorname{Rank}\left[G, F G, \cdots, F^{n-1} G\right]=n
$$

【定義 2】1) (observability) 零入力のシステム $\Sigma$ に対し任意の時刻 $t_{0}$ の状態 $x_{0}$ が， $t_{0}$ から $t\left(>t_{0}\right)$ までの時間区間の出力から一意に与えられるとき $x_{0}$ は observable な状態であるという。状態空間 $R^{n}$ の

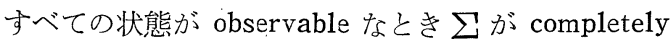
obsərvableといら.

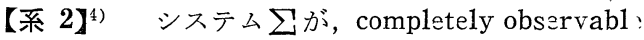
であるための必要十分条件は，

$\operatorname{Rank}\left[H^{T}, F^{T} H^{T}, \cdots, F^{T n-1} H^{T}\right]=n$

一般の completety controllable でないシステム の状態 $x$ に関しては,

【系 3】 值域の 1 点ならばかつこのときに限り $x$ は controllable である。

【定義 $\mathbf{1}^{\prime}$ 状態 $x$ が $W W^{T}$ の零空間の 1 点の ときこのときに限り $x$ は uncontrollable という.

【系 4】 状態 $x$ が $M \triangleq\left[H^{T}, F^{T} H^{T}, \cdots, F^{T n-1}\right.$ $H^{T}$ ] の值域の 1 点ならば, かつこのときに限り $x$ は observable である.

【定義 $2^{\prime}$ 状態 $x$ が $M M^{T}$ の零空間の 1 点の ときこのときに限り $x$ は unobservable という。

すなわち，一般のシステム $\sum$ は，

【定理 1】 $\left(\mathrm{Kalman}^{4)}\right)$ システム $\sum$ は，正則な $n \times n$ 行列 $T$ により, 状態空間の基底を変えると,

$$
\begin{gathered}
x=T x^{\prime} \\
x^{\prime}(t+1)=\left[\begin{array}{cccc}
F^{11}, & F^{12}, & F^{13}, & F^{14} \\
0, & F^{22}, & 0, & F^{24} \\
0, & 0, & F^{33}, & F^{34} \\
0, & 0, & 0, & F^{44}
\end{array}\right] x^{\prime}(t)+\left[\begin{array}{c}
G^{1} \\
G^{2} \\
0 \\
0
\end{array}\right] u(t) \\
y(t)=\left[0, H^{2}, 0, H^{4}\right] x^{\prime}(t) \\
\text { ただし, } x^{\prime T}=\left(x_{1}^{\prime T}, x_{2}{ }^{T}, x_{3}{ }^{T}, x_{4}{ }^{T}\right) \\
x_{1}{ }^{\prime}: n_{1}{ }^{\prime}, x_{2}{ }^{\prime}: n_{2}{ }^{\prime}, x_{3}{ }^{\prime}: n_{3}{ }^{\prime}, x_{4}{ }^{\prime}, x_{4}{ }^{\prime}: n_{4}{ }^{\prime} \text { vectors }\left(n_{1}\right. \\
\left.+n_{2}+n_{3}+n_{4}=n\right), x_{1}{ }^{\prime} \text { は controllable だが unobser- }
\end{gathered}
$$


bable な状態， $x_{2}^{\prime}$ は controllable かつ obs:rvable な状態, $x_{3}{ }^{\prime}$ は uncontrollable, unobservable な状態, $x_{4}{ }^{\prime}$ は uncontrollable だが observable な状態.

このとき（7)，（8）式で記述されるシステムの伝 達関数 $R(z)$ は,

$$
R(z)=H^{2}\left(I z-F^{22}\right)^{-1} G^{2}
$$

で与えられる。（定理 1 終）

いっ湾ら，パルス伝達関数 $R(z)$ が与えられるとき， 状態変数記述でどのように表わされるかを考える。 $R(z)$ のすべての要素 $r_{i j}(z)$ の分母の $z$ の多項式の 最小公倍式が $1+\alpha_{1} z^{-1}+\alpha_{2} z^{-2}+\cdots+\alpha_{l} z^{-l}$ なるとき $R(z)$ を $R(z, l)$ で表わす. $R(z, l)$ は,

$$
R(z, l)=\frac{1}{1+\alpha_{1} z^{-1}+\cdots+\alpha_{l} z^{-l}}\left[\Gamma_{1} z^{-1}+\cdots+\Gamma_{l} z^{-l}\right]
$$

ただし， $\Gamma_{i}: p \times m$ matrix $i=1, \cdots, l \quad \Gamma_{i}$ は，

$$
\Gamma_{i}=\left[\begin{array}{l}
r_{i 1}{ }^{T} \\
\gamma_{i p}{ }^{T}
\end{array}\right]
$$

\section{と表わす。}

【定理 2】 $R(z, l)$ が与光られるとき最小次元実 現が存在し, 最小次元実現を求めるアルゴリズムが存 在する。

【証明】 (10) 式で伝達関数が与えられる多変数 系は次の observable standard form で記述される.

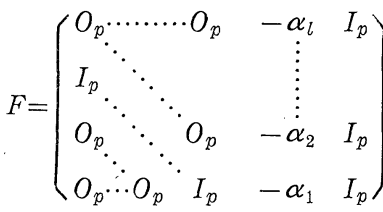

$$
\begin{aligned}
& G=\eta^{-1} \times\left[\begin{array}{c}
\Gamma_{l} \\
\vdots \\
\dot{\Gamma}_{1}
\end{array}\right] \\
& H=\eta\left[O_{p}, \cdots, O_{p}, I_{p}\right]
\end{aligned}
$$

ただし, $O_{p}$ は $p \times p$ の zero matrix, $I_{p}$ は $p \times p$ の identity matrix (12) 式で与えられるシステム, $F, G$, $H$ は系 2 より completely observable である.この システム $\sum$ の状態空間で controllable な部分空間は 系 3 より $W=\left[G, F G, \cdots, F^{n-1} G\right]$ の值域である。 $W$ の定義域を $U$ とし， $\sum$ の状態空間を $X_{\Sigma}$ とすれば，

$$
W: U \rightarrow X_{\Sigma}
$$

$W^{T} W$ の零でない固有值を $\lambda_{1}, \lambda_{2}, \cdots, \lambda_{n_{0}}$ とし，年れ に対応する正規固有ベクトルを $v_{1}, v_{2}, \cdots, v_{n_{0}}$ とす る.

$$
W^{T} W v_{i}=\lambda_{i} v_{i} \quad i=1, \cdots, n_{0}
$$

すると $W W^{T}$ \& $\lambda_{1}, \lambda_{2}, \cdots, \lambda_{n_{0}}$ を固有值としてもち, 対応する正規固有べクトルを $\omega_{1}, \omega_{2}, \cdots, \omega_{n_{0}}$ とすると，

$$
W W^{T} \omega_{i}=\lambda_{i} \omega_{i} \quad i=1, \cdots, n_{0}
$$

(14), (15) 式加ら,

$$
\omega_{i}=\lambda_{i}{ }^{-(1 / 2)} W v_{i}
$$

すなわら

$$
\begin{gathered}
\operatorname{Range}(W)=\operatorname{Range}\left(W W^{T}\right) \\
X_{\Sigma}=\operatorname{Range}(W) \oplus \operatorname{Null}\left(W W^{T}\right)
\end{gathered}
$$

と表わされる. $\operatorname{Rank}[W]=n_{0}$ であるから Ranga $(W)$ を張る $n_{0}$ 個の正規直交基底 $S=\left(\omega_{1}, \cdots, \omega_{n \jmath}\right)$ を 選ぶ。同様に $\operatorname{Nul1}\left(W W^{T}\right)$ ，を張る $n-n_{0}$ 個の $S$ に 対して正規直交な基底 $\omega_{n_{0}+1}, \cdots, \omega_{n}$ を考光る.

$$
T=\left[\omega_{1}, \cdots, \omega_{n}\right]
$$

とすると $T$ を基底として表わした状態 $x^{\prime}$ は，

$$
x=T x^{\prime}
$$

で表わされる. Range $(W)$ は $F$ で invariant な空 間であるから，

$$
\begin{gathered}
x^{\prime}(t+1)=\left[\begin{array}{cc}
F_{0}, & F^{12} \\
0, & F^{22}
\end{array}\right] x^{\prime}(t)+\left[\begin{array}{c}
G_{0} \\
0
\end{array}\right] u(t) \\
y(t)=\left[H_{0}, H^{2}\right] x^{\prime}(t)
\end{gathered}
$$

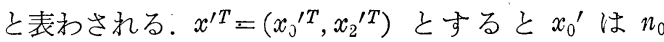
vector の controllable かつ observable な状態, $x_{2}^{\prime}$ は $n-n_{0}$ vector の obsərvable だが uncontrollable の状態である. $S^{T}=V$ とすると，

$$
\begin{aligned}
V S & =I_{n_{0}} \\
F_{0} & =V F S \\
G_{0} & =V G \\
H_{0} & =H S
\end{aligned}
$$

しかるに定理 1 より $\left\{F_{0}, G_{0}, H_{0}\right\}$ は $R(z, l)$ の最小次 元実現になっている. (定理 2 終)

定理 2 にって一般に勝手に $l$ を選んで $R(z, l)$ で システムを同定すると controllable から obsarvable な状態以外に uncontrollable あるいは unobsrvable な状態を導入することになることがわかる。すなわら 同定したモデルを用いて制御あるいは観測に使用でき ない，それゆ光最小次元実現で入出力が規定されるシ ステムを表現することが望ましい.

\section{3. 入力出力が与えられる場合の同定法}

本章では入力データ $\{u(0), u(1), \cdots, u(N-1)\}$, 出 力データ $\{y(0), \cdots, y(N)\}$ が与えられる場合の実現 問題を考える. 定理 2 からこれらを入出力としてもつ システムの伝達関数を求めれば，内部記述が求まるこ とが示された，それゆ光，まず入力出力データが与え られた場合にこれらを満たすと仮定した に対する伝 達関数 $R(z, l)$ が存在するかどらかが問題となる. こ の問題に対して次の主定理をらる。

【主定理】 入出力データ $\{u(i): i=0, \cdots, N-1\}$ $\{y(i): i=0, \cdots, N\}$ が与兄られるとき，これが伝達関 
数 $R(z, l)$ をもつシステムの入力出力であるための必 要十分条件は,

$$
Q_{N}{ }^{l}=\frac{1}{N-l+1} \sum_{l=l}^{N} L_{t}{ }^{l T} L_{t}{ }^{l}
$$

なる行列の固有值に零があり; それに対応する固有べ クトルの第 1 成分が零でないことである。

$$
\begin{aligned}
& \text { ただし， } \\
& L_{t}^{l}=\left[y_{t}, y_{t-1}, \cdots, y_{t-l}, u_{t-1}, \cdots, u_{t-l}\right]
\end{aligned}
$$

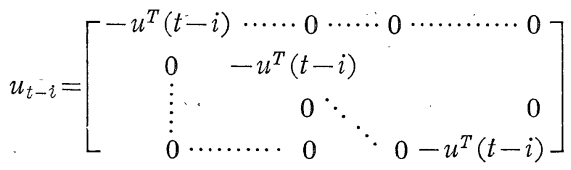

$$
\begin{aligned}
& p \times m p \text { matrix }
\end{aligned}
$$

【証明】（必要条件であること）与えられたデー タが， $R(z, l)$ の入出力であるならば,

$$
\begin{gathered}
y(t)=R(z, l) u(t) \quad(t=0, \cdots, N) \\
\phi^{T}=\left(1, \alpha_{1}, \alpha_{2}, \cdots, \alpha_{l}, \gamma_{11}{ }^{T}, \gamma_{12}{ }^{T}, \cdots, \gamma_{l p}{ }^{T}\right)
\end{gathered}
$$

とすると (28) 式加ら，

$$
L_{t}{ }^{l} \phi=0 \quad t=l, \cdots, N
$$

(30）式に $L_{t}{ }^{l T}$ をか抙和をとると,

$$
\sum_{t=l}^{N} L_{t}{ }^{l T} L_{t}{ }^{l} \phi=(N-l+1) Q_{N}{ }^{l} \phi=0
$$

(31) 式から $\phi$ は $Q_{N} l$ の固有值零に刘応する固有心 クトルであり (29) 式の $\phi$ の定義より $\phi$ の第 1 要素 は零でない.

（十分条件であること） $Q_{N}^{l}$ が固有值に零があり， それに対応する固有ベクトル $\psi$ の第 1 要素が零でな いとすると，

$$
\sum_{t=l}^{N} L_{t}{ }^{l T} L_{t}{ }^{l} \psi=0
$$

(32) 式に $\psi^{T}$ をかけると，

$$
\sum_{t=l}^{N}\left\|L_{t}^{l} \psi\right\|^{2}=0
$$

$(32)^{\prime}$ から,

$$
L_{t}^{l} \psi=0 \quad t=l, \cdots, N
$$

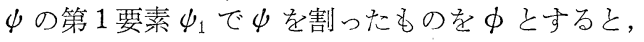

$$
\begin{gathered}
\phi=\phi / \psi_{1} \\
L_{t}{ }^{l} \phi=0 \quad t=l, \cdots ; N
\end{gathered}
$$

すなわち $\alpha_{1}=\phi_{2}, \alpha_{3}=\phi_{3}, \cdots, \alpha_{l}=\phi_{l+1}$,

$$
\Gamma_{i}=\left[\begin{array}{l}
\phi_{(i-1) p m+i+2}, \cdots, \phi_{(i-1) p n+l+m+1} \\
\phi_{i p m+l-m+2}, \cdots, \phi_{i p m+l+1}
\end{array}\right]
$$

とすると（35）式から入力出力は（10）式の伝達関数 を満たす。（主定理終）

【系 5】主定理の条件が満足されるとき，伝達関 数 $R(z, l)$ の未知パラメータ $\phi$ は,

$$
\phi=\phi / \psi_{1}
$$

で与えられる。ただし $\psi$ は $Q_{N}^{l}$ の零固有值に対する 固有ベクトルで $\psi_{1}$ はその第 1 要素.

主定理と系 5 から入力出力データが与えられるとき $R(z, l)$ がある $l$ に刘し存在するかどらか, 存在すれ ばその未知パラメータがさめられる。もしある $l$ に対 し, 主定理の条件が満足しない場合, 満足するまで $l$ を増やせばよい，次に主定理の条件を満たす $R(z, l)$ が与兄らても, この $R(z, l)$ が uncontrollable and/or unocs rvableな状態を表現している可能性が あるとき，

$$
R(z, l)=R\left(z, l^{\prime}\right) \quad l^{\prime} \leq l
$$

なる $l^{\prime}$ が存在する。（36）式の最小の $l^{\prime}$ に対する $R\left(z, l^{\prime}\right)$ は定理 2 から,

$$
R\left(z, l^{\prime}\right)=H_{0}\left(z I-F_{0}\right)^{-1} G_{0}
$$

以上から $R(z, l)$ 方存在するとき, 系 5 より $\phi$ を 求め次に定理 2 から最小次元実現システム $\Sigma\left(F_{0}\right.$, $\left.G_{0}, H_{c}\right)$ を同定する。 $\Sigma_{2}$ のまま制御あるいは観測の モデルとして使用しても良いし (37)' 式から $R\left(z, l^{\prime}\right)$ を求めても良い。

\section{4. ノイズに污されたデータが与えられる 場合}

前章で有限長の入力出力データが与えられる場合こ の入力出力関係を満たす最小次元システムを同定する 万法を述べた。しかし，一般の同定問題に和いては， 入力 $u(t)$, 出力 $y(t)$ は,

$$
\begin{aligned}
& v(t)=u(t)+\mu(t) \\
& z(t)=y(t)+\nu(t)
\end{aligned}
$$

とノイズ $\mu(t), \nu(t)$ に污されたデータ $\{v(t): t=0$, $\cdots, N-1\}\{z(t): t=0, \cdots, N\}$ が与光られる. $\mu(t)$, $\nu(t)$ を平均値零, 分散 $\sigma^{2}$ の互いに独立なエルゴード 性をも方色雑音之仮定する。

$$
E\left(\mu_{i}(t)\right)=E\left(\nu_{j}(t)\right)=0 \quad i=1, \cdots, m, j=1, \cdots, p
$$

$E\left(\mu(t) \mu^{T}(\tau)\right)=\sigma^{2} I_{m} \delta_{t \tau}, \quad E\left(\nu(t) \nu^{T}(\tau)\right)=\sigma^{2} I_{p} \delta_{t \tau}$

ただし，Eは数学平均を示す。

(26) 式の $L_{t}{ }^{2}$ と同じょうに,

$$
\widetilde{L}_{t}^{l} \triangleq\left[z_{t}, z_{t-1}, \cdots, z_{t-l}, V_{t-1}, \cdots, V_{t-l}\right]
$$
ただし，

$$
V_{t-i}=\left[\begin{array}{ccc}
-v^{T}(t-i) & 0 \cdots \cdots \cdots \cdots & 0 \\
0 & -v^{T}(t-i) & \vdots \\
\vdots & \cdots & 0 \\
0 & \ldots & 0-v^{T}(t-i)
\end{array}\right]
$$

すると $L_{t}^{l}$ と $\widetilde{L}_{t}^{l}$ は次の関係を満たす。

$$
E\left(L_{l} l T L_{t}^{l}\right)=E\left(\widetilde{L}_{t} l T \widetilde{L}_{t}^{l}\right)-\sigma^{2} \Lambda
$$


ただし，

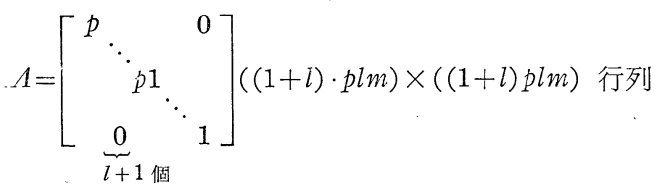

すなわち $\widetilde{L}_{t}{ }^{l}$ が与えられれば $E\left(\widetilde{L}_{t}^{l T} \widetilde{L}_{t}^{l}\right)$ :を求めるこ とができる，仮定から，

$$
E\left(\widetilde{L}_{t}{ }^{l T} \widetilde{L}_{t}{ }^{l}\right)=\lim _{N \rightarrow \infty} \frac{1}{N-l+1} \sum_{i=i}^{N} \widetilde{L}_{t}{ }^{l T} \widetilde{L}_{t}^{l},
$$

すなわら十分大きな $N$ に対して，

$$
\frac{1}{N-l+1} \sum_{t=l}^{N} \widetilde{L}_{t}{ }^{l} \widetilde{L}_{t}{ }^{l}-\sigma^{2} \Lambda \triangleq \bar{Q}_{N} l \cong Q_{N}{ }^{l}
$$

。 $\sigma^{2}$ が既知の場合 $\bar{Q}_{N} l$ ，の最小固有值に対応する固有へ クトルから系 5 を用いて未知パラメー夕を求める。十 分大きな $l$ に対しても $N$ が有限なら最小固有値は零 にはならないが，実際㵊小固有值が十分小さけれ ば，主定理を満たしていると考省て良い。このように して求めた $R(z, l)$ から定理 2 と同様の方法で, 実際 的観点からの最小次元実現を求める。これには approximately controllable $\mathrm{e}^{9)}$ と類似の $\varepsilon$-practically controllableなる考光方を導入する。

【定義 3】 $W W^{T}\left(M M^{T}\right)$ のとより大きい固有值 に対応する固有ベクトルルよって張られる部分空間の 要素を $\varepsilon$-practically controllabla ( $\varepsilon$-practically obsərvable) という.

この考方方は, 時刻 0 で零状態にあるシステムは時 刻 $t$ では,

$$
x(t)=\sum_{i=1}^{t} F^{t-i} G u(i-1)
$$

Caley-Hamilton の定理から ${ }^{10)}$,

$$
x(t)=\sum_{i=1}^{n} F^{i-1} G u_{i}=W u
$$

$$
u=\left(\begin{array}{c}
u_{1} \\
\vdots \\
u_{n}
\end{array}\right) \quad m \times n \text { vector をU の要素とする. }
$$

$W W^{T}$ の零でない固有值を $\lambda_{1}, \cdots, \lambda_{n}$ としそれに対応 する正規固有ベクトルを $\omega_{1}, \cdots, \omega_{n^{\prime}}$ とし $W W^{T}$ の零 空間と張る線形独立ベクトルを $\omega_{n^{\prime}+1}, \cdots, \omega_{n}$ ，とする。

$W^{T} W$ の固有值も (14)，(15）式から $\lambda_{1}, \cdots, \lambda_{n^{\prime}}$ とな り，対応する正规固有ベクトルを $v_{1}, \cdots, v_{n^{\prime}}$ とし $W^{T} W$ の零空間を張る線形独立ベクトルを $V_{n^{\prime}+1}, \cdots$, $x_{n m}$ とする.

$$
\begin{aligned}
& x=\left(\omega_{1}, \cdots, \omega_{n}\right) x^{1} \\
& u=\left(v_{1}, \cdots, v_{n m}\right) u^{\prime}
\end{aligned}
$$

と $x, u$ の基底を変光ると，

$$
x(t)=\left(\omega_{1}, \cdots, \omega_{n}\right) x^{\prime}=W\left(v_{1}, \cdots, v_{n m}\right) u^{\prime}
$$

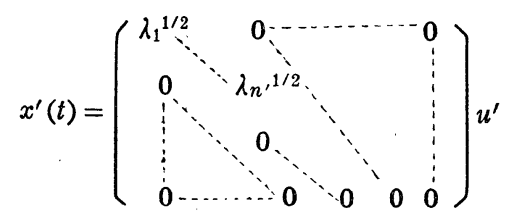

しかるに, $\quad \lambda_{n_{0}+1}, \cdots, \lambda_{n^{\prime}}<\varepsilon$

なるとき，

$$
x_{i}{ }^{2} \leq \varepsilon\left\|u^{\prime}\right\|^{2} \quad i=n_{0}+1, \cdots, n^{\prime}
$$

(53) 式からをが少さいとき $x_{i}\left(i=n_{0}+1, \cdots, n^{\prime}\right)$ は 他の状態变数に比べ害際的見地より practically uncontrollable 之考光て良い.

また $\varepsilon$-practically ołservability についても同様 の議論ができる。これに対し次の定義 6 をする。

【定義 6】 $\varepsilon$-practically controllable, observable なる状態だけでンステムを表現したものをと-minimal realization といら.

【定理 3】 $\varepsilon$-minimal rsalization は, $M M^{T} の$ すべての固有値が 次にこのように定められた $W$ に対し $\lambda\left(W W^{T}\right)>\varepsilon$ を 满たす正規固有ベクトル $\omega_{1}, \cdots, \omega_{n_{0}}$ から，

$$
\begin{gathered}
S_{0}=\left[\omega_{1}, \cdots, \omega_{n_{0}}\right] \\
V_{0}=\left[\begin{array}{c}
\omega_{1}^{T} \\
\omega_{n_{0}}{ }^{T}
\end{array}\right]
\end{gathered}
$$

とするとき，

$$
F_{0}=V_{0} F S_{0}, G_{0}=V_{0} G, H_{0}=H S_{0}
$$

で与えられる。

証明は定理 2 と定義 5 の説明より明らかである.

(46) 式の $\sigma^{2}$ が未知のとき十分大きくlをとり $\Lambda^{-1} \frac{1}{N-l+1} \sum_{t=l}^{N} \widetilde{L}_{t}{ }^{l T} \widetilde{L}_{t}{ }^{l}$ の最小固有值の固有ベクトル から， $F_{0} ， G_{0}, H_{0}$ を求め, $l+1$ の場合に求めた $F_{0}$ の次元と比べ, $l+1$ のときのほうの $F_{0}$ の次元が大き いなら $l+2$ をとる操作をする. $l$ と $l+1$ が $F_{0}$ の 次元が同じとき, $\Lambda^{-1} \frac{1}{N-l+1} \sum_{t=1}^{N} \widetilde{L}_{t}{ }^{l T} \widetilde{L}_{t}{ }^{l}$ の最小固有 值が近似的に $\sigma^{2}$ であることが (46) 式からわかる.

\section{5. 例 題}

これまで多変数系の同定法を提案したが, この方法 をはっきり示すため単一変数系へ応用した場合を例に 示す。

【例題 1】（57）式のパルス伝達関数を持つシス テムのノイズに污されない入出力データ $\{u(t), y(t)$, $t=0, \cdots, 48\}$ が与兄られた。

$$
R(z)=\frac{0.75 z^{-1}-0.25 z^{-2}}{1-0.85 z^{-1}+0.5 z^{-2}}
$$


このとき $Q_{48}{ }^{5}$ の固有值が零で第 1 要素が 1 の固有べ クトル $\phi$ は, $\phi^{T}=(1,5.525,80.286,-23.014,3.313,23.111$ $0.75,4.531,62.310,13.365,-11.556)$

すなわち入出カデータから 5 次のシステム，

$$
R(z, 5)=\frac{\phi_{7} z^{-1}+\phi_{8} z^{-2}+\phi_{9} z^{-3}+\phi_{10} z^{-4}+\phi_{11} z^{-5}}{1+\phi_{2} z^{-1}+\phi_{3} z^{-z}+\phi_{4} z^{-3}+\phi_{5} z^{-4}+\phi_{6} z^{-5}}
$$

が同定された。(57)'式の obsミrve canonical form は $\eta=1$ に対し,

$$
F=\left(\begin{array}{ccccc}
0 & 0 & 0 & 0 & -\phi_{6} \\
1 & 0 & 0 & 0 & -\phi_{5} \\
0 & 1 & 0 & 0 & -\phi_{4} \\
0 & 0 & 1 & 0 & -\phi_{3} \\
0 & 0 & 0 & 1 & -\phi_{2}
\end{array}\right)
$$

$$
G=\left(\begin{array}{c}
\phi_{11} \\
\phi_{10} \\
\phi_{9} \\
\phi_{8} \\
\phi_{7}
\end{array}\right)
$$

$$
H^{T}=\left(\begin{array}{l}
0 \\
0 \\
0 \\
0 \\
1
\end{array}\right)
$$

$W=$

$$
\left(\begin{array}{rrrrr}
-11.556 & -17.333 & -8.956 & 1.054 & 5.374 \\
13.365 & 14.041 & -18.617 & -8.804 & 1.825 \\
62.310 & 30.626 & -5.123 & -19.667 & -14.156 \\
4.531 & 2.095 & -0.485 & -1.460 & -0.998 \\
0.75 & 0.388 & -4.563 & -0.233 & -0.175
\end{array}\right)
$$

$W W^{T}$ の固有值は $5851.707,958.6566,0,0,0$, である．零でない2つの固有值に対応する正規固有べ クトルを $\omega_{1}, \omega_{2}$ とし $S=\left[\omega_{1}, \omega_{2}\right]$ とすると, $V=S^{T}$ は，

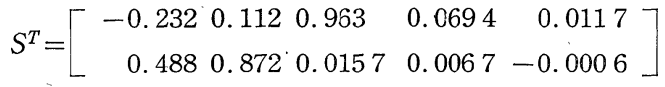

(59)，(61）式を（24）式に代入する之,

$$
\begin{gathered}
F_{0}=\left[\begin{array}{rr}
0.4013 & 0.8836 \\
-0.3621 & 0.4486
\end{array}\right] \quad G_{0}=\left[\begin{array}{r}
64.528 \\
7.023
\end{array}\right] \\
H_{0}{ }^{T}=\left[\begin{array}{r}
0.0117 \\
-0.0006
\end{array}\right]
\end{gathered}
$$

(62) 式で $\left[F_{0}, G_{0}, H_{c}\right]$ の与えられるシステムの伝達 関数は,

$$
H_{\mathrm{c}}\left[I z-F_{0}\right]^{-1} G_{0}=\frac{0.75 z^{-1}-0.25 z^{-2}}{1-0.85 z^{-1}+0.5 z^{-2}}
$$

をらる。

【例題 2】例題 1 と同じ (57) 式の伝達関数をも つシステムの, 分散 $\sigma^{2}=0.05^{2}$ のノイズで污された入
出力データ $\{v(t), z(t), t=0, \cdots, 48\}$ が与兄られた. 分散を未知とし $\frac{1}{N-l+1} \sum_{t=l}^{N} \widetilde{L}_{t} l T \widetilde{L}_{t}^{l}$ の最小固有値 0.001394 に刘する第 1 要素が 1 の固有ベクトルは, $\phi^{T}=(1,1.1846,0.8327,0.3900,0 . C 80,0.5311$, $0.7625,1.2801,1 .(603,0.3321,-0.2566)$

(64) 式から (57 $)^{\prime}$ ，(59) 式と同様にパルス伝達関数を 求められ，このシステムを実現する observe canonica1 form $[F, G, H]$ が求められる。 $\eta=1$ のとき $M M^{T}$ の固有値は 6.512, 3.4514,1.2058,0.3161,0.1167 であるから $\varepsilon=0.01$ のとき $\eta=1$ として良い。この， ときの $W$ は,

$W=$

$\left(\begin{array}{rrrrr}-0.2566 & -0.4049 & -0.2002 & 0.0109 & 0.1353 \\ 0.3321 & -0.3176 & -0.4351 & -0.1986 & 0.0313 \\ 1.0603 & 0.0347 & -0.4646 & -0.4271 & -0.0992 \\ 1.2801 & 0.4259 & -0.2790 & -0.4475 & -0.2149 \\ 0.7625 & 0.3769 & -0.2051 & -0.2548 & -0.1457\end{array}\right)$

$W W^{T}$ の固有值は $4.544,0.672,0.00207,0.000215$, 0.000089 であるから $\varepsilon=0.01$ より大きい固有值に対 応する正規固有ベクトルを $\omega_{1}, \omega_{2}$ とし $S=\left[\omega_{1}, \omega_{2}\right]$. は前の例題同様 $V=S^{T}$ であり, $S^{T}=$

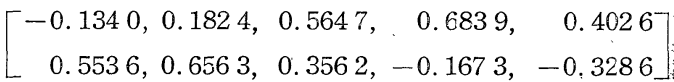

定理 3 より (66) 式を用いて $\varepsilon$-practically minimal realization を求めると,

$$
\begin{gathered}
F_{0}=\left[\begin{array}{r}
0.2530,1.0455 \\
-0.3248,0.5783
\end{array}\right] \\
G_{0}=\left[\begin{array}{r}
1.8765 \\
-0.0109
\end{array}\right]
\end{gathered}
$$$$
H_{0}=\left[\begin{array}{lll}
0.4026, & 0.3286
\end{array}\right]
$$

（67）式より同定されたシステムの伝達関数は,

$$
H_{0}\left(I z-F_{0}\right)^{-1} G_{\mathrm{C}}=\frac{0.759 z^{-1}-0.242 z^{-2}}{1-0.8313 z^{-1}+0.4859 z^{-2}}
$$

（57）式と比較し，(68）式は良好な同定結果を与えて いる．以上より $R(z, l)$ を主定理と系 5 から求め，定 理 2 を用いて最小次元実現あるいはデータにノイズの ある場合は $\varepsilon-$ 最小次元実現が求められることを示し た。 との選び方としてはなんら定量的な方法はこれま で与えなかったがたと光ば，

$$
\varepsilon=\frac{1}{100} \min \left\{\lambda_{1}, \cdots, \lambda_{n_{0}}\right\}
$$


などが考劣らるであろら。

また最小次元実現から伝達関数を求めることにより， これをでむずかしかった次数の決定も容易に行なえる ことがわかる。

\section{6. 結}

論

最近の実現問題の成果を用いて, 多变数系の実際的 同定法を与光た。その結果同定されたシステムの構造 に注意を払うべきであることがわかった。これは，こ れまでのパラメータ推定に重点を拁いた同定法では求 められなかったことがらであり，「次元が大きければ 大きい汪ど正確なモデル」といわれたものが，実は uncontrollable unobservable な状態をるつ制御にも 観測に使えないモデルを与えることになることを示し た、特にこれまで発達した実現理論を実際に応用する ため, $\varepsilon$-practically controllability, $\varepsilon$-practically observability そ $\varepsilon$-minimal realization なる概念を 導入し，これまでのパラメータ推定に重点を置いた同 定法をシステムの構造を考慮することにより, 次数の 決定をで含んだ実際的同定法に改善する方向を示した。 これらの結果はンステム理論を実際活用する道を示 したといえるであるう。

終わりに本研究について御討論くださったフロリダ 大学の R.E. Kalman 教授に感謝致します.またこの 研究をするに当たり昭和 46 年度松永研究助成金を一
部使用させていただき亲した。ここに明記して感謝致 します。

\section{参 考 文 献}

1) K. J. Åstrom \& P. Eykhoff : Identification and Process Parameter Estimation, Preprint of 2nd IFAC Symp. on Identification (1970)

2) A. V. Balakushran \& V. Deterka: Identification in a Automatic Control Systems, Survey Paper at 4 th Congress of IFAC (1969)

3) A.P. Sage \& J.L. Melsa: System Identification, Academic Press (1971)

4) R.E. Kalman et al. : Topics in Mathematical System Theory McGraw Hill (1969)

5) E.G.Gilbert : Controllability and Obseruability in Multivariable Control Systems, SIAM Control, 1-2, 128/151 (1963)

6) D. Q. Mayne : Computational Procedure for the Minimal Realization of Transfer-function Matrix, Rroc. IEE, 115-9, Sept. 1363/1368 (1968)

7) B.L.Ho \& R.E.Kalman : Effective Construction of Linear State-Variable Models from Input/Output Functions, Regelungs Technik 14, Jahrg Heft 12, $545 / 548$ (1966)

8) K. Furuta \& J.G. Daquet: On the Taentfication of Time-Invariant Discrete Process, IEEE-AC, 15-1, 153/155 (1970)

9) H. A. Antosiewicz : Linear Controllability in $\Gamma \mathrm{Fu}$ nctional Analysis and Optimization」Academic Press (1966)

10) L. A. Zadeh C. A. Desoer : Linear System Theory, McGraw Hill, 498/499 (1963) 